Témoigner Témoigner. Entre histoire et mémoire

Getuigen Revue pluridisciplinaire de la Fondation Auschwitz

$122 \mid 2016$

Révisionisme et négationisme

\title{
Nadia Tahir, Argentine. Mémoires de la dictature
}

\section{David Jurado}

\section{OpenEdition}

\section{Journals}

\section{Édition électronique}

URL : https://journals.openedition.org/temoigner/4715

DOI : 10.4000/temoigner.4715

ISSN : 2506-6390

\section{Éditeur :}

Éditions du Centre d'études et de documentation Mémoire d'Auschwitz, Éditions Kimé

\section{Édition imprimée}

Date de publication : 2 mai 2016

Pagination : 174-175

ISSN : 2031-4183

\section{Référence électronique}

David Jurado, «Nadia Tahir, Argentine. Mémoires de la dictature », Témoigner. Entre histoire et mémoire [En ligne], 122 | 2016, mis en ligne le 30 septembre 2021, consulté le 12 janvier 2022. URL : http:// journals.openedition.org/temoigner/4715; DOI : https://doi.org/10.4000/temoigner.4715

Ce document a été généré automatiquement le 12 janvier 2022.

Tous droits réservés 


\title{
Nadia Tahir, Argentine. Mémoires de la dictature
}

\author{
David Jurado
}

\section{RÉFÉRENCE}

Nadia Tahir, Argentine. Mémoires de la dictature, Renne, Presses universitaires de Renne, « Des Amériques », 2015, 266 p.

\section{Les associations de victimes face à la mémoire}

1 La bibliographie récente sur les questions de mémoire des victimes de la dernière dictature militaire argentine démontre à quel point cet enjeu se pose aujourd'hui avec acuité, même hors des frontières du pays. (Voir par exemple les travaux de Claudia Feld, Elizabeth Jelin, Daniel Lvovich et Jaquelina Bisquert). Depuis les années 2000, la mémoire joue un rôle central dans le débat public du pays, ce dont témoigne une prolifération de musées, de monuments, de commémorations et de productions culturelles. Cependant, cette éclosion récente résulte d'un processus long et complexe et toute généralisation nuirait à la compréhension de ce phénomène. C'est pourquoi le livre de Nadia Tahir, Argentine. Mémoires de la dictature, est particulièrement utile. Issu de sa thèse de doctorat, cet ouvrage retrace la vie des associations de victimes, notamment celles des Mères et des Grands-Mères de la Place de Mai, depuis leur fondation jusqu'au mandat présidentiel de Néstor Kirchner. D'une part, l'auteure décrit les formes d'organisation de ces associations, la transformation de leurs stratégies en fonction des discours officiels des différentes périodes présidentielles. D'autre part, elle analyse les dynamiques d'échanges, de soutien ou les conflits que ces associations entretiennent entre elles, mais aussi les associations de défense de droits de l'homme, leurs contradictions internes. Enfin, leur rapport au débat international sur les crimes contre l'humanité est l'un des enjeux de l'ouvrage. 
2 Loin de se limiter à la description de l'histoire de chaque association, Nadia Tahir examine la subjectivité des discours mémoriels à travers une analyse de documents publiés par les associations et d'une recherche de terrain. Ainsi, elle réussit à démontrer comment le passé de cette dictature, à travers un processus de sélection, de négociation et de réinterprétation, devient mémoire collective. Lors de la crise économique, par exemple, les associations optent pour un discours qui assimile les luttes sociales des années 1970 à celles de la fin des années 1990 et du début des années 2000. De cette manière, elles réinvestissent leur propre combat par le biais des sensibilités culturelles, des interrogations éthiques et des accords politiques du présent. Ces dynamiques sont constantes, car la présence sur la scène publique des récits mémoriels revendiqués par les associations est essentielle pour que la justice puisse être rendue. La constitution d'une mémoire collective relève, en effet, d'un enjeu moral et éthique. De surcroît, Nadia Tahir révèle comment convergent les récits portés par les différentes associations, les outils discursifs et les actions concrètes qu'elles développent et réinventent pour rester dans l'actualité de la vie politique du pays.

Nadia Tahir met ainsi en valeur la transcendance de ces associations dans l'histoire récente du pays, transcendance qui différencie l'Argentine des pays voisins partageant des expériences de répression similaires. Le cas argentin, explique-t-elle, «se distingue non seulement par son actualité avec la multiplication des procédures judiciaires à l'encontre de personnes ayant participé à la répression dictatoriale et la récupération des centres clandestins de détention, mais aussi parce que ces associations sont toujours des acteurs majeurs de la sphère publique argentine. » (p. 254)

Il faut souligner également que la singularité du cas argentin réside dans la consolidation des associations composées par des membres des familles des victimes. Ainsi existe-t-il non seulement des associations des Mères et Grands-Mères, mais aussi des fils (H I J O S.) et des frères et sœurs (Herman@s). À cet effet, au travers d'une analyse des discours des Grands-Mères de la Place de Mai, Gabriel Gatti ("Imposing Identity against Social Catastrophes. The Strategies of (Re)Generation of Meaning of the Abuelas de Plaza de Mayo (Argentina)", Bulletin of Latin American Research, vol. 31, $\mathrm{n}^{\circ} 3$, 2012, p. 352-365) indique comment, dans la recherche de justice, celles-ci étaient parvenues à légitimer une définition de l'identité par des liens du sang. Cette définition de l'identité est, selon l'auteur, pré-moderne dans la mesure où l'identité se réduit alors à la filiation naturelle ou au code génétique. Toutefois, ce discours s'est révélé efficace dans la recherche de justice de la part des associations. D'autant plus que le statut de victimes, comme l'explique Nadia Tahir, est assimilé aux « détenus-disparus ». Ainsi, la disparition d'une personne et par conséquent d'un lien familial est-il au cœur du processus militant argentin. Pour leur part, les survivants des centres clandestins de détention sont plutôt considérés comme victimes que comme témoins. Ce phénomène, difficile à expliquer, prend ses racines dans la suspicion entourant les détenus libérés, bien qu'il ait été prouvé par la suite que les libérations ont été arbitraires et faisaient partie des stratégies militaires de contrôle.

5 Au travers de cette étude de cas, Nadia Tahir se démarque des approches historiques plus vastes qui perdent de vue la spécificité et la diversité des formes d'engagement des associations. C'est une étude nécessaire pour comprendre les processus de mémoire, la construction de l'histoire récente de l'Argentine, mais aussi pour appréhender le rôle historique majeur des associations dans le processus de retour à la démocratie, sans pour autant tomber dans la glorification. 